\title{
Optimization of the ultrasonic-microwave assisted enzymatic hydrolysis of freshwater mussel meat
}

\author{
Yajun Zhou ${ }^{1}$, Xiaoli Yi ${ }^{1}$, Jingya Wang ${ }^{1}$, Qi Yang ${ }^{1}$, Shujie Wang ${ }^{2 *}$ \\ (1. Department of Food Science and Engineering, Jilin University, Changchun 130062, China; \\ 2. College of Biological and Agricultural Engineering, Jilin University, Changchun 130025, China)
}

\begin{abstract}
In the present study, the Ultrasonic-Microwave (US-MW) technique was applied for assisting enzymatic hydrolysis of freshwater mussel meat. The operating parameters of enzymatic hydrolysis were investigated and the properties and qualities of the freshwater mussel hydrolysates were also analyzed. The considerable optimum conditions for enzymatic hydrolysis of mussel meat were ratio of liquid to material of $10.36: 1$, power of $360.52 \mathrm{~W}$, processing time of $6.91 \mathrm{~min}$, enzymolysis time of $4 \mathrm{~h}$. Under these conditions, a degree of hydrolysis (DH) of $48.40 \%$ was obtained. The hydrolysates produced under optimum conditions, were characterized in terms of electrophoretic profile, amino acid composition and infrared spectrum analysis. SDS-PAGE profiles of the hydrolysates revealed that several protein bands were cleaved and several light myosin chains ( $25 \mathrm{kDa}$ and $15 \mathrm{kDa}$, respectively) and peptides of molecular weight lower than $6.5 \mathrm{kDa}$ were identified. The infrared spectrum absorption peak of amide band A and band III shifted after US-MW pre-treatment, which indicated that the N-H (hydrogen bonding) stretching vibration and triple helix structure of samples were affected. The essential amino acids in hydrolysates with or without US-MW pre-treatment were $36.62 \mathrm{mg} / 100 \mathrm{~g}$ and $33.40 \mathrm{mg} / 100 \mathrm{~g}$. It was proved that US-MW assisted enzymatic hydrolysis is an effective technology to utilize freshwater mussel meat.
\end{abstract}

Keywords: ultrasonic-microwave (US-MW), freshwater mussel meat, enzymatic hydrolysis, degree of hydrolysis (DH)

DOI: $10.25165 /$ j.ijabe.20181105.4104

Citation: Zhou Y J, Yi X L, Wang J Y, Yang Q, Wang S J. Optimization of the ultrasonic-microwave assisted enzymatic hydrolysis of freshwater mussel meat. Int J Agric \& Biol Eng, 2018; 11(5): 236-242.

\section{Introduction}

Freshwater mussel, belonging to bivalve mollusk, because of their fast-growing ability, high reproductive capacity, and strong adaptability, is a main source used for culturing pearls ${ }^{[1,2]}$. However, after culturing pearls, most mussels were discarded, causing not only a waste of source but also pollute the environment ${ }^{[3]}$. In fact, mussel meat has a high nutritional value. Compared with other meat product, such as beef and pork, mussel meat has higher protein, lower fat and calories ${ }^{[4,5]}$. Besides, it also has kinds of essential amino-acids, polyunsaturated fatty acids and many rare minerals such as selenium, calcium, iron, magnesium, phosphorous and vitamins (A, B1, B2, B6, B12 and C ${ }^{[6,7]}$.

In recent years, more and more researchers study on mussel to add the value for human consumption, but most of them placed more emphases on the storage techniques of marine mussels ${ }^{[8,9]}$. Nevertheless, the study about the processing of freshwater mussel was rarely reported.

Ultrasound is an acoustic wave with a frequency greater than $20 \mathrm{kHz}$, the frequency is above the human hearing threshold ${ }^{[10]}$. Ultrasound can produce high shear and mechanical energy due to the cavitation phenomenon ${ }^{[11]}$. Therefore, it can be used to

\section{Received date: 2018-01-11 Accepted date: 2018-04-29}

Biographies: Yajun Zhou, PhD, Professor, research interests: food processing and preservation, Email: zhouruyilang@163.com; Xiaoli Yi, Graduate, research interests: food processing and preservation, Email: yixiaoli727@163.com; Jingya Wang, Undergraduate, research interests: food processing and preservation, Email: wangjyhhh@163.com; Qi Yang, Undergraduate, research interests: food processing and preservation, Email:18843008665@163.com.

*Corresponding author: Shujie Wang, $\mathrm{PhD}$, Professor, research interests: agricultural bioinformatics. College of Biological and Agricultural Engineering, Jilin University, Changchun 130025, China. Tel: +86-431-85094968, Email: w.sj123@yahoo.com. modify the structures and properties of globular proteins. Recently, several studies have provided evidence on the use of ultrasound pre-treatment to improve the enzymatic hydrolysis and properties of proteins ${ }^{[12,13]}$. Microwave assisted extraction is a new technology to improve the extraction efficiency by using microwave energy. US-MW synergistic technology combines ultrasonic vibration and open microwave, fully utilized the cavitation interaction of ultrasonic vibration and the high energy of microwave ${ }^{[14]}$. It is efficient and safe, widely applying in food industry, biomedicine, environmental science, chemistry and chemical industry ${ }^{[15]}$. However, US-MW assisted enzymatic hydrolysis of freshwater mussel meat has never reported.

The aim of this study was to investigate the US-MW assisted enzymatic hydrolysis of freshwater mussel meat adopting response surface methodology (RSM), to produce a hydrolysate that could be used as flavoring or protein supplement. The hydrolysate obtained under the optimal condition was evaluated by the degree of hydrolysis (DH), electrophoretic profile, amino acid composition and infrared spectrum.

\section{Materials and methods}

\subsection{Materials}

Freshwater mussels were purchased from Songhua River Basin (Jilin, China). Mussel tears and other splanchnic tissues were removed. The selected ones were cut into pieces and ground with colloid mill, then kept frozen at $-18^{\circ} \mathrm{C}$ until analysis. The contents of ash and protein were obtained according to AOAC. The crude fat was measured according to Lee et al. ${ }^{[16]}$ and Undeland et al. ${ }^{[17]}$ with some modifications. The main characteristics of mussel meat were, on a wet weight basis, $11.56 \pm 0.22 \mathrm{~g} / 100 \mathrm{~g}$ of proteins, $4.00 \pm 0.11 \mathrm{~g} / 100 \mathrm{~g}$ of lipids and $1.80 \pm 0.14 \mathrm{~g} / 100 \mathrm{~g}$ of ash. 
The commercial papain was purchased from Pangbo biotechnology company, which is food grade, with declared activity of $8.0 \mathrm{AU} / \mathrm{g}$.

\subsection{Methods}

\subsubsection{Enzymatic hydrolysis}

The hydrolysis experiments were carried out in beakers using water-bathing constant temperature vibrator. Adding suitable amount of freshwater mussel meat into beakers, homogenized with distilled water (ratio of material to liquid, w/v). Homogenate was pretreated by combined ultrasonic and microwave device at different power, processing time. The $\mathrm{pH}$ was adjusted with $0.5 \mathrm{~N}$ $\mathrm{NaOH}$. Papain was added to the mixture and the reaction was carried out at $50^{\circ} \mathrm{C}$. A Box-Behnken design was used to determine the optimum hydrolysis conditions using 4 independent variables: ratio of material to liquid $(1: 8-1: 12 \mathrm{~g} / \mathrm{mL})$, power (200-400 W), processing time (5-7 min), enzymolysis time (3-5 h). Totaling 29 combinations was shown in Table 1.

Table 1 Hydrolysis variables and experimental design levels for response surface analysis

\begin{tabular}{ccccc}
\hline \multirow{2}{*}{$\begin{array}{c}\text { Design } \\
\text { levels }\end{array}$} & $\begin{array}{c}\text { Ratio of liquid to } \\
\text { material }\end{array}$ & Power/W & $\begin{array}{c}\text { Processing } \\
\text { time/min }\end{array}$ & $\begin{array}{c}\text { Enzymolysis } \\
\text { time } / \mathrm{h}\end{array}$ \\
\hline-1 & 8 & 200 & 5 & 3 \\
0 & 10 & 300 & 6 & 4 \\
1 & 12 & 400 & 7 & 5 \\
\hline
\end{tabular}

The enzyme was inactivated by heating the solution to $85^{\circ} \mathrm{C}$ for $15 \mathrm{~min}$ and then the resulting solution was cooled at room temperature and centrifuged at $4000 \mathrm{r} / \mathrm{min}$ for $20 \mathrm{~min}$ to get hydrolysate.

\subsubsection{Determination of $\mathrm{DH}$}

Take the supernatant solution of the enzymolysis solution, add the same amount of TCA solution of $20 \%$ concentration, centrifuged at $5000 \mathrm{r} / \mathrm{min}, 4^{\circ} \mathrm{C}$ for $15 \mathrm{~min}$. Then collect the concentration of $10 \%$ TCA-solution material, the $\mathrm{DH}$ is determined as follows:

$\mathrm{DH}=($ Total amount of $\mathrm{N}$ in $10 \%$ TCA-solution material - Non protein nitrogen content in samples)/Total $\mathrm{N}$ content in the sample $\times 100 \%$

where, the determination of protein content was by Kjeldahl method.

\subsubsection{Amino acid analysis}

Total and free amino acids in raw mussels and in the enzymatic hydrolysate from isolated mussel meat were analyzed by HPLC according to Fontaine and Eudaimon ${ }^{[18]}$.

2.2.4 Sodium dodecyl sulfate-polyacrylamide gel electrophoresis (SDS-PAGE)

Electrophoresis was performed on the protein hydrolysate and mussel meat, according to Schagger and Jagow ${ }^{[19]}$.

\subsubsection{Infrared spectrum analysis}

Mussel meat pre-treated with or without US-MW were scanned by infrared spectroscopy with $\mathrm{KBr}$ disks method. The $\mathrm{KBr}$ was placed in the oven at $130^{\circ} \mathrm{C}$ for $5 \mathrm{~h}$, stored in a desiccator for measure. Two milligram mussel meat protein samples of freeze drying and $200 \mathrm{mg} \mathrm{KBr}$ were mixed. The mixture was ground into powder (about 15 min grinding) in an agate mortar, pressed into a tablet machine. The pressed samples were placed in the sample chamber for determination (Sample room was filled with desiccant). The Scanning range was $4000-400 \mathrm{~cm}^{-1}$. The whole operation process should be carried out in an infrared lamp, and maintain indoor humidity at a low level, the operating process with gloves all the time.

\subsubsection{Statistical analysis}

Data were analyzed by Excel (Microsoft Corporation, Redmond, WA, USA) and analysis of variance used Design Expert Version 8.0. Differences between treatment means at the $5 \%$ level were determined using Duncan's multiple range test. Each process version was repeated three times $(n=3)$ unless noted otherwise. The RSM was used to optimize the enzymatic hydrolysis for the maximum $\mathrm{DH}$.

\section{Results and discussion}

\subsection{Effect of ratio of material to liquid on the DH}

The effect of ratio of material to liquid on the $\mathrm{DH}$ was showed in Figure 1. When the ratio of material to liquid decreased from $1: 4$ to $1: 10$, the $\mathrm{DH}$ increased obviously. After that, with the increase of ratio, the DH decreased. It is generally accepted that when the ratio of material to liquid was at a low level, the viscosity of the material was too high to flow, the substrate and enzyme can not be smoothly or effectively combined, which restricted the normal reaction. However, the probability of substrate combined with enzyme was increased since the ratio induced to a suitable level, casing the DH increased. But when the ratio of material to liquid in a further increase, although the liquidity of solution became better, the concentration of substrate and enzyme decreased at the same time, the efficiency of effective combination between enzyme and substrate has been reduced, so the DH decreased.

As shown in Figure 1, the DH was higher with US-MW pre-treatment at the same ratio. The probable reason was that the structure of mussel meat protein was relatively complex and the polypeptide chains tightly folded together to form Tertiary or Quaternary structure, which could hinder enzymatic hydrolysis to some degre $\mathrm{e}^{[20]}$. However, the use of ultrasonic-microwave treatment could destroy the structure of mussel meat protein, make its firm structure become loose. The enzyme sites that wrapped in intramolecular were exposed to improve the effect of enzymatic hydrolysis.

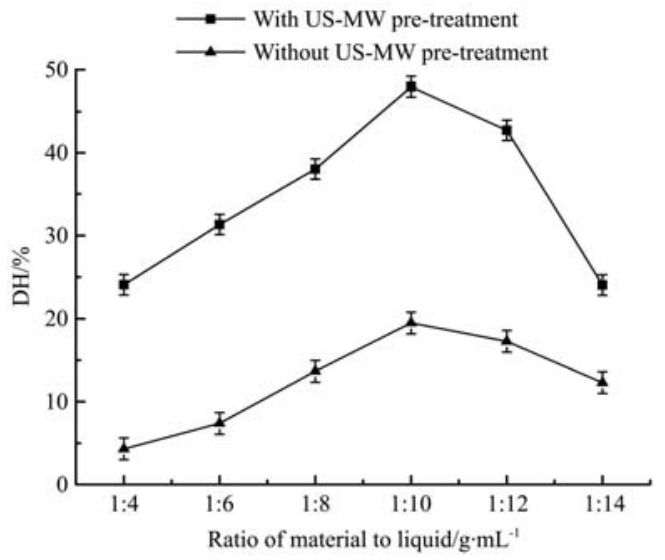

Figure 1 Effect of ratio of material to liquid on DH

\subsection{Effect of enzymolysis time on the DH}

Figure 2 showed that in the initial stage of the reaction, the reaction speed was quick, this may due to the newly added papain has a higher concentration of active enzyme. However, with the extension of time, papain gradually inactivated, the effective concentration of the enzyme reduced ceaselessly, resulted in the reaction rate gradually slowing down. As time prolonged, the reaction got into the later period, most of the enzyme was inactivated and products were accumulated, the reaction equilibrium shifted to the left, so the reaction seemed to stop. After $5 \mathrm{~h}$, the DH slightly increased, but it was not obvious. 


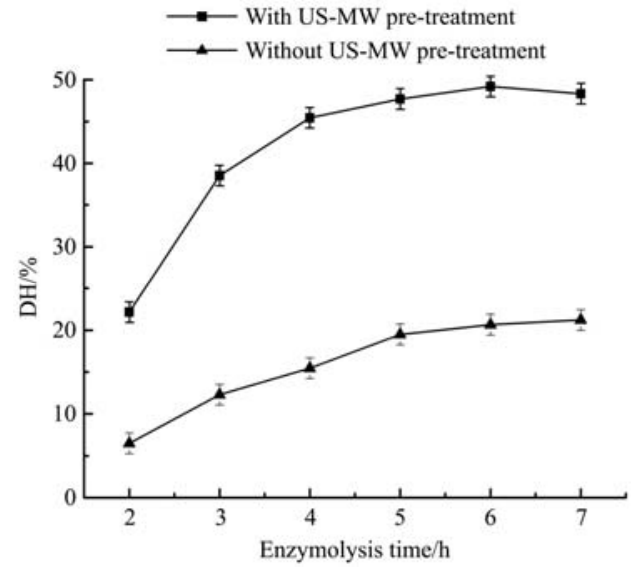

Figure 2 Effect of enzymolysis time on DH

\subsection{Effect of processing time on the DH}

In Figure 3, when the processing time was lower than $6 \mathrm{~min}$, the DH increased with the increasing of processing time, but when the processing time was higher than $6 \mathrm{~min}$, the DH decreased. The cell membrane of reactant was destroyed when ultrasonic and microwave worked together, and the intracellular substance was released, then it got a full contacted with solvent, thereby the reactions were accelerated. However, the microwave irradiation time increased with the prolonging of processing time. The temperature of reaction system also increased, the longer the time was, the higher the temperature was. When the temperature was too high, the protein denatured and precipitated, and the enzymatic hydrolysis process was blocked, so the DH decreased.

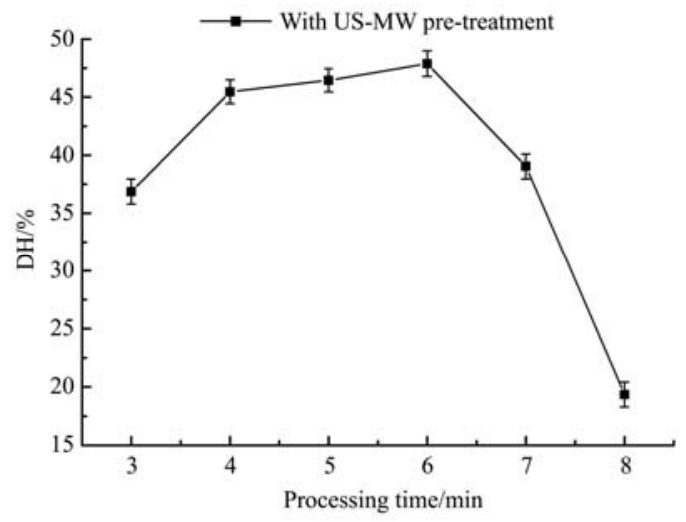

Figure 3 Effect of processing time on DH

\subsection{Effect of power on the DH}

In Figure 4, there was a positive correlation between the DH and power when the power was less than $300 \mathrm{~W}$. However, if we continue to increase the power, the $\mathrm{DH}$ decreased sharply. The reason may be that a sharp rise in power leads to an increase in temperature, when the power increased, the temperature reached the desired temperature in less time than the original. In addition, ultrasonic treatment also resulted in an increase in the $\alpha$-helix component and a decrease in the $\beta$-sheet component ${ }^{[21]}$. With the increase of ultrasonic power, time and temperature, the decrease of quantity in the $\beta$-sheet component declined. This phenomenon might be attributed to the fact that the high ultrasonic power, temperature and time accelerated protein moleculars motion, increased the chance of protein moleculars collision, and rearranged protein molecules at the interface. The protein molecules which had exposed to the surface of the molecules, were buried inside the molecules ${ }^{[22]}$. However, in the higher power, the temperature rose rapidly, and at a higher temperature may damage the protein structure or make the protein denatured, made the $\mathrm{DH}$ decreased sharply.

The DH of protein of ultrasonic-microwave assisted enzymatic hydrolysis was higher than that from general enzymatic hydrolysis (Figures 1-4). It was about twice more. These might be attributed to the fact that the ultrasound pre-treatment broke internal hydrophobic interactions of protein molecules, increased hydrophobic areas inside the molecules to be exposed to the surface of the molecules ${ }^{[23]}$. This result indicated that ultrasonicmicrowave could markedly improve the DH of freshwater mussel protein. This provides the basis for the deep processing of mussel meat.

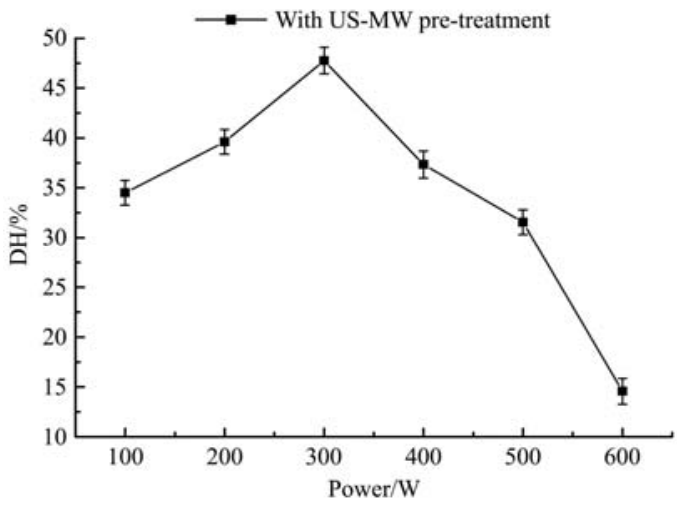

Figure 4 Effect of power on DH

3.5 Optimization of the US-MW assisted enzymatic hydrolysis of mussel meat

Results of the DH are showed in Table 2. The fitted models proposed for $\mathrm{DH}$ is as follow:

$$
\begin{aligned}
& Y(\%)=48.56+0.18 X_{1}+0.22 X_{2}+0.12 X_{3}+0.037 X_{4}-0.31 X_{1} X_{2}+ \\
& 0.020 X_{1} X_{3}-0.27 X_{1} X_{4}+0.20 X_{2} X_{3}-0.27 X_{2} X_{4}-0.37 X_{3} X_{4}- \\
& 0.89 X_{1}^{2}-0.82 X_{2}^{2}-0.59 X_{3}^{2}-0.59 X_{4}^{2}
\end{aligned}
$$

where, $Y$ is the degree of hydrolysis, $\% ; X_{1}$ is the ratio of liquid to material; $X_{2}$ is the power, $X_{3}$ is the processing time, $X_{4}$ is the enzymolysis time. The determination coefficient $\left(R^{2}=0.9651\right)$ was satisfactory, having a low experimental error according to ANOVA (Table 2). The ratio of liquid to material $\left(X_{1}\right)$, power $\left(X_{2}\right)$ and processing time $\left(X_{3}\right)$ had a significant effect $(p<0.05)$ at the maximum DH. The ratio of liquid to material-power $\left(X_{1} X_{2}\right)$ and ratio of liquid to material-enzymolysis time (AD) interaction term had a significant effect $(p<0.05)$, otherwise, power, interaction term processing time- enzymolysis time and the quadratic terms $\left(X_{1}^{2}, X_{2}^{2}\right.$ and $\left.X_{3}^{2}\right)$ also had a highly significant effect $(p<0.001)$. When one of the variables is fixed at the central point and the other two are allowed to vary are shown in Figure 5. The maximum predicted value is indicated by the surface confined in the smallest ellipse in the contour diagram. It indicated that there is relatively significant interaction between the ratio of liquid to material and power corresponding to the response surface, which is consistent with the results of the ANOVA for quadratic model.

Figure 5 and Tables 2 and 3 showed that the value of DH vary from $46.02 \%$ to $48.15 \%$. Similar results were found by Kurozawa et al. ${ }^{[24]}$ and de Holanda and Netto ${ }^{[25]}$.

The optimal conditions for the hydrolysis of the Freshwater mussel meat were ratio of liquid to material of $10.36: 1$, power of $360.52 \mathrm{~W}$, processing time of $6.91 \mathrm{~min}$, enzymolysis time of $4 \mathrm{~h}$. Under such conditions, the DH was $48.40 \%$. In the previous study, the DH $(52.4 \%)$ in the one-stage hydrolysis of Alaska pollack meat by mixed Protamex and Flavozyme was higher than that in the two-stage hydrolysis $(48.1 \%)^{[26]}$. This was the same as the results of the study of $\mathrm{Hu}$ et al. ${ }^{[27]}$ 
Table 2 Experimental design and results of response surface analysis

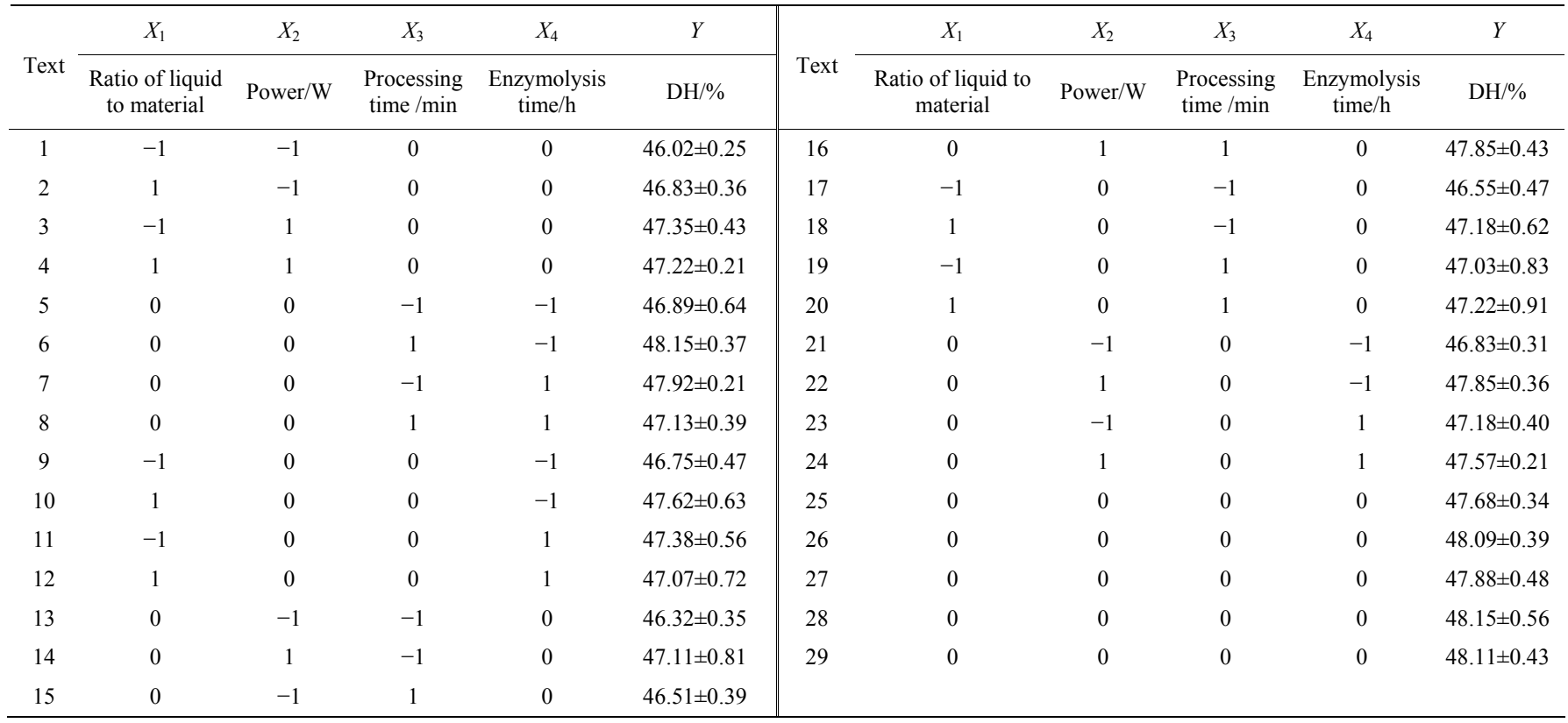

Note: Values are presented as means $\pm \operatorname{SD}(n=3)$
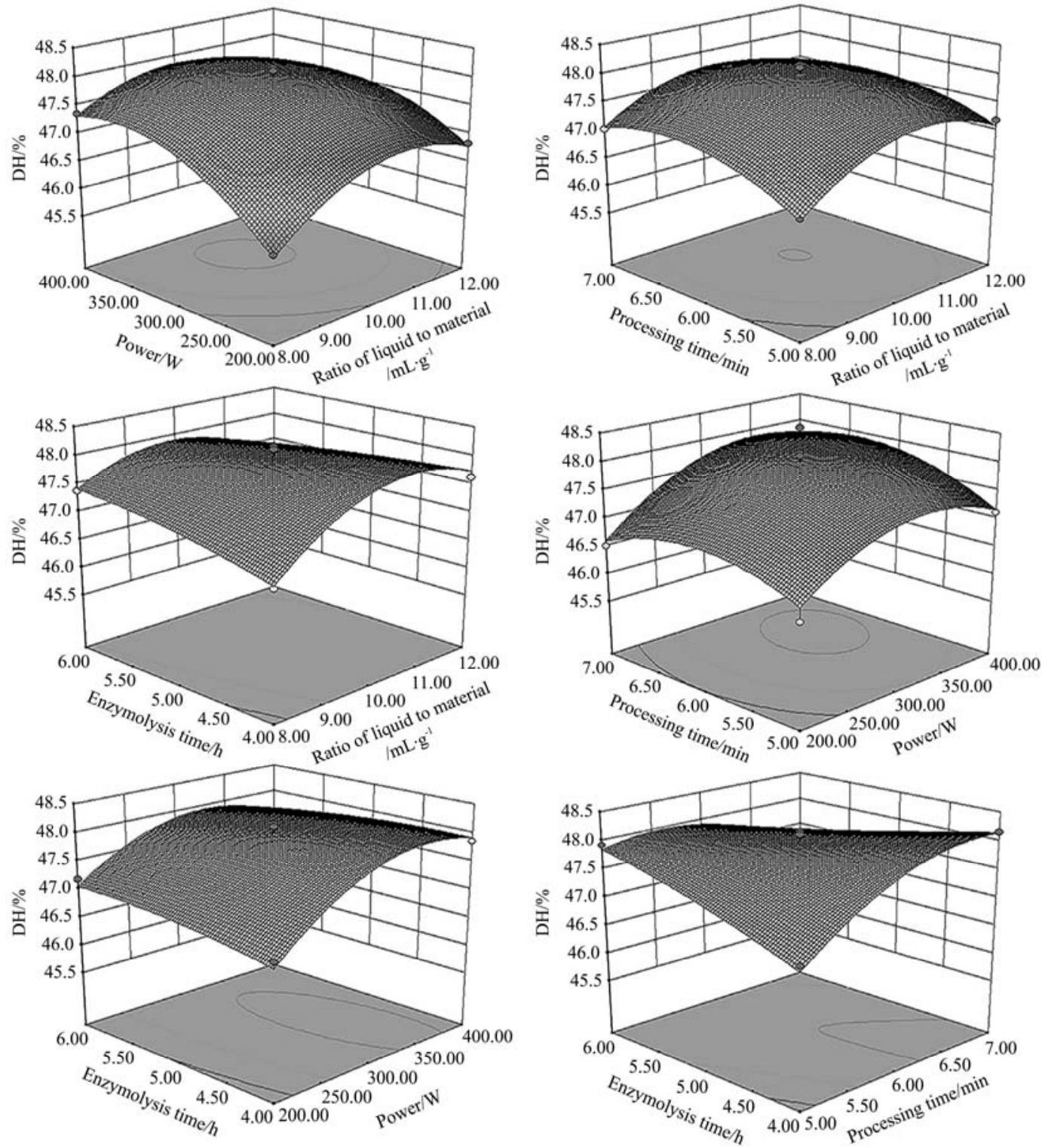

Figure 5 Response surfaces graphs depicting effects of independent variables on DH during US-MW assisted enzymatic hydrolysis of freshwater mussel meat 
Table 3 Analysis of variance for the response of design of hydrolysis

\begin{tabular}{cccccc}
\hline Source & Sum of Squares & $d f$ & Mean Square & $F$ Value & Prob $>F$ \\
\hline Model & 8.98 & 14 & 0.64 & 27.64 & $<0.0001^{* *}$ \\
$X_{1}$ & 0.35 & 1 & 0.35 & 15.24 & $0.0016^{* *}$ \\
$X_{2}$ & 2.31 & 1 & 2.31 & 99.33 & $<0.0001^{* *}$ \\
$X_{3}$ & 0.31 & 1 & 0.31 & 13.23 & $0.0027^{* *}$ \\
$X_{4}$ & $2.13 \times 10^{-3}$ & 1 & $2.13 \times 10^{-3}$ & 0.092 & 0.7662 \\
$X_{1} X_{2}$ & 0.22 & 1 & 0.22 & 9.52 & $0.0081^{* *}$ \\
$X_{1} X_{3}$ & 0.048 & 1 & 0.048 & 2.09 & 0.1707 \\
$X_{1} X_{4}$ & 0.35 & 1 & 0.35 & 15 & $0.0017^{* *}$ \\
$X_{2} X_{3}$ & 0.076 & 1 & 0.076 & 3.26 & 0.0926 \\
$X_{2} X_{4}$ & 0.099 & 1 & 0.099 & 4.27 & 0.0577 \\
$X_{3} X_{4}$ & 1.05 & 1 & 1.05 & 45.26 & $<0.0001^{* *}$ \\
$X_{1}^{2}$ & 2.42 & 1 & 2.42 & 104.18 & $<0.0001^{* *}$ \\
$X_{2}^{2}$ & 2.02 & 1 & 2.02 & 87.04 & $<0.0001^{* *}$ \\
$X_{3}^{2}$ & 1.07 & 1 & 1.07 & 45.97 & $<0.0001 * *$ \\
$X_{4}^{2}$ & 0.059 & 1 & 0.059 & 2.55 & 0.1324 \\
Residual & 0.32 & 14 & 0.023 & & 0.8768 \\
Lack of fit & 0.17 & 10 & 0.017 & 0.42 & \\
Pure error & 0.16 & 4 & 0.039 & & \\
Cor Total & 9.31 & 28 & & & \\
\hline & 1 & 1 & & & \\
\hline
\end{tabular}

Note: \% variability explained $R^{2}=0.9651, R_{a d j}{ }^{2}=0.9302 . \quad * p<0.01$ (extremely significant), $* * p<0.05$ (significant).

In order to test the reliability of the results obtained from the Box-Behnken test design, the optimization process parameters were extracted for 3 times, the measured average yield is $48.35 \%$. Compared with the theoretical prediction, the relative error is $0.45 \%$. This means that the optimal model is reliable.

\subsection{Amino acid profile}

Table 4 showed the amino acids composition of the mussel meat and hydrolyzate. As shown in the Table 4, they all contained a total of 17 common amino acids, including 9 essential amino acids (EAA) and 8 nonessential amino acids (NEAA). Glutamic acid, leucine, aspartic acid, lysine and arginine were the major amino acids, accounting for $50 \%$ to $52 \%$ of the total FAA. This result was in accordance with Silva et al. ${ }^{[28]}$ The contents of glutamic, proline, glycine, and alanine were all improved after enzymatic hydrolysis. Especially the glutamic, which contributed umami taste as delicious amino acid together with aspartic ${ }^{[29]}$. This will donate much to Maillard reaction to produce a flavor liquor.

Table 4 showed that the content of taste amino acid of hydrolyzate with US-MW was higher than that without US-MW $(50.05 \mathrm{~g} / 100 \mathrm{~g}$ and $45.26 \mathrm{~g} / 100 \mathrm{~g}$, respectively). The hydrolysates contained very high levels of lysine ( $8.3 \%$ of the total amino acids) which is extremely rare in cereals and required for proper development and acts as precursor for production of carnitine, a nutrient with roles in converting fatty acids into energy and regulating cholesterol levels. Arginine is classified as a semi-essential or conditionally essential amino acid and it participates in protein synthesis and other physiological functions such as detoxification and energy conversion ${ }^{[30]}$.

\subsection{SDS-PAGE profile}

SDS-PAGE as an efficient method, is used to distinguish proteins. With the combination of SDS and protein, it can form more electronegative compounds. These negative charges are much more than the original charge of the protein molecules. This phenomenon covers or removes the charge differences among protein molecules and makes the mobility of protein-SDS complex in gel electrophoresis relate to the molecular weight of the protein molecules themselves ${ }^{[31]}$.

Table 4 Total amino acid composition of mussel meat and protein hydrolysis under optimum conditions

\begin{tabular}{|c|c|c|c|}
\hline \multirow{2}{*}{ Amino acid } & \multicolumn{3}{|c|}{ Amino acid content $/ \mathrm{mg} \cdot 100 \mathrm{~g}^{-1}$} \\
\hline & Mussel meat & $\begin{array}{c}\text { Hydrolyzate } \\
\text { without US-MV }\end{array}$ & $\begin{array}{c}\text { Hydrolyzate with } \\
\text { US-MV }\end{array}$ \\
\hline Aspartic acid (Asp) & $10.25 \pm 0.21$ & $7.72 \pm 0.03$ & $9.83 \pm 0.06$ \\
\hline Threonine* (Thr) & $4.75 \pm 0.32$ & $3.68 \pm 0.06$ & $4.52 \pm 0.14$ \\
\hline Serine (Ser) & $5.21 \pm 0.12$ & $4.66 \pm 0.12$ & $5.16 \pm 0.18$ \\
\hline Glutamic acid( Glu) & $16.65 \pm 0.13$ & $16.2 \pm 0.13$ & $17.31 \pm 0.23$ \\
\hline Proline (Pro) & $4.52 \pm 0.03$ & $5.69 \pm 0.21$ & $6.02 \pm 0.04$ \\
\hline Glycine( Gly) & $6.50 \pm 0.05$ & $8.98 \pm 0.26$ & $9.37 \pm 0.17$ \\
\hline Alanine (Ala) & $6.12 \pm 0.12$ & $6.71 \pm 0.09$ & $6.89 \pm 0.11$ \\
\hline Valine $^{*}($ Val $)$ & $5.13 \pm 0.16$ & $5.04 \pm 0.16$ & $5.11 \pm 0.16$ \\
\hline Methionine $^{*}$ (Met) & $2.13 \pm 0.06$ & $1.98 \pm 0.11$ & $2.05 \pm 0.01$ \\
\hline Isoleucine ${ }^{*}$ (Ilu) & $4.98 \pm 0.32$ & $4.14 \pm 0.14$ & $4.64 \pm 0.03$ \\
\hline Leucine $^{*}$ (Leu) & $8.35 \pm 0.21$ & $7.37 \pm 0.02$ & $8.09 \pm 0.21$ \\
\hline Tyrosine (Tyr) & $3.05 \pm 0.17$ & $2.15 \pm 0.07$ & $2.76 \pm 0.06$ \\
\hline Phenylalanine $^{*}$ (Phe) & $4.50 \pm 0.19$ & $3.50 \pm 0.03$ & $3.95 \pm 0.0$ \\
\hline Lysine $^{*}$ (Lys) & $8.28 \pm 0.08$ & $7.69 \pm 0.19$ & $8.26 \pm 0.08$ \\
\hline Histidine (His) & $2.12 \pm 0.15$ & $1.93 \pm 0.10$ & $2.01 \pm 0.02$ \\
\hline Arginine (Arg) & $7.45 \pm 0.05$ & $8.10 \pm 0.15$ & $8.30 \pm 0.12$ \\
\hline Tryptophan (Try) & - & - & - \\
\hline Essential amino acid & $38.12 \pm 1.34$ & $33.4 \pm 0.71$ & $36.62 \pm 0.63$ \\
\hline Total taste amino acid & $47.07 \pm 0.87$ & $45.26 \pm 0.61$ & $50.05 \pm 0.63$ \\
\hline
\end{tabular}

Note: * was essential amino acid, values are presented as means $\pm \operatorname{SD}(n=3)$.

The SDS-PAGE profiles of the mussel meat (column 1) and hydrolysate (columns 2 and 3) are shown in Figure 6. In column 1 , several protein bands were identified in mussel meat, there were more big molecular protein and less small molecular proteins. According to Margulis and Pinaev ${ }^{[32]}$, the main components of mussel miofibrils are heavy myosin chain $(200 \mathrm{kDa})$, paramiosin $(105 \mathrm{kDa})$, actin $(45 \mathrm{kDa})$, tropomyosin $(30 \mathrm{kDa}$ to $39 \mathrm{kDa})$, and light myosin chain $(16 \mathrm{kDa})$. Columns 2 and 3 were hydrolysate with or without US-MW pre-treatment. In columns 2 and 3, it can be seen that two clear protein bands were in the similar molecular weight band. This phenomenon indicated that the US-MW treatment had almost no effect on the molecular weight of mussel protein.

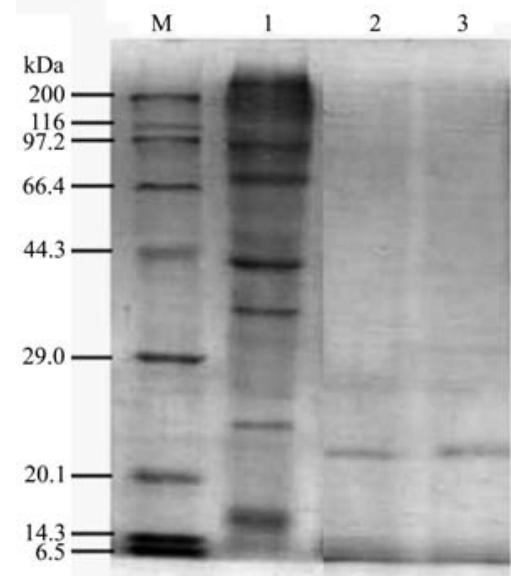

Note: M: Markers; 1: mussel meat; 2: general enzymatic hydrolysis; 3: US-MW assisted enzymatic hydrolysis.

Figure 6 SDS-PAGE profile of mussel meat 


\subsection{Infrared spectrum analysis}

Figures 7 and 8 show that the band absorption peaks of amide band A, B, I, II and III of mussel meat protein without pre-treatment by US-MW appeared at around $3342 \mathrm{~cm}^{-1}, 2929 \mathrm{~cm}^{-1}$, $1651 \mathrm{~cm}^{-1}, 1539 \mathrm{~cm}^{-1}$ and $1249 \mathrm{~cm}^{-1}$, respectively. And the band absorption peaks of that with pre-treatment by US-MW appeared at around $3362 \mathrm{~cm}^{-1}, 2929 \mathrm{~cm}^{-1}, 1651 \mathrm{~cm}^{-1}, 1539 \mathrm{~cm}^{-1}$ and $1246 \mathrm{~cm}^{-1}$, respectively.

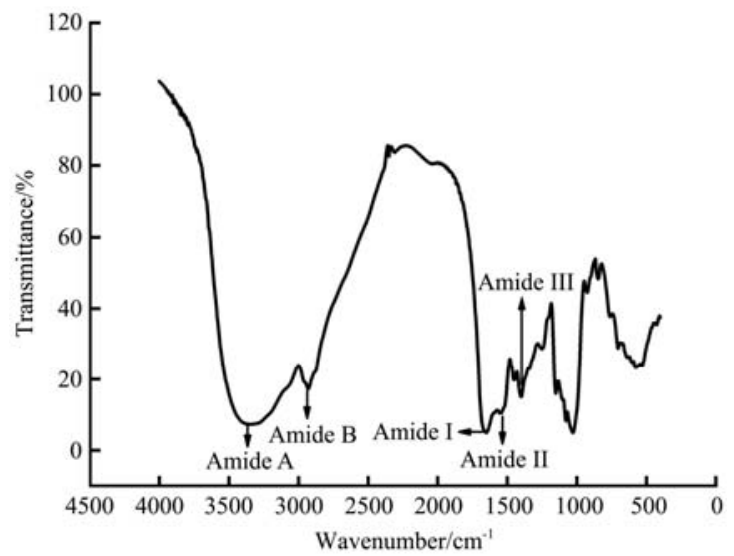

Figure 7 Infrared spectrum of mussel meat protein with general enzymatic hydrolysis

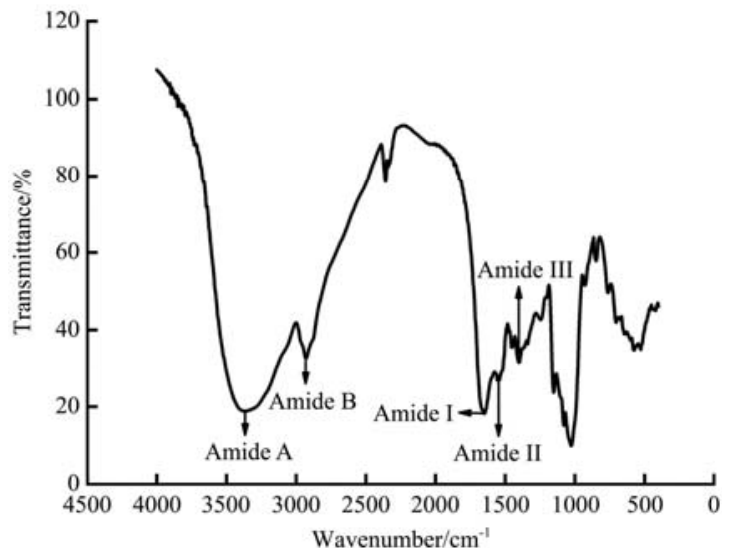

Figure 8 Infrared spectrum of mussel meat protein with US-MW assisted enzymatic hydrolysis

The N-H (hydrogen bond) stretching vibration peak of amide band A appeared near 3200-3600 $\mathrm{cm}^{-1}$. After US-MW treatment, the absorption peak position of amide band A shifted from $3342 \mathrm{~cm}^{-1}$ to $3362 \mathrm{~cm}^{-1}$, and the peak was slightly narrowed. The results showed that US-MW has some influence on the N-H (hydrogen bond) stretching vibration of amide band A.

Amide band B appeared at around $2929 \mathrm{~cm}^{-1}$, which is related to the asymmetric stretch of $-\mathrm{CH}_{2}{ }^{[33]}$. Amide band I appeared at around $1651 \mathrm{~cm}^{-1}$, in general, amide band I should appear between $1600 \mathrm{~cm}^{-1}$ and $1700 \mathrm{~cm}^{-1}$, mainly related with stretching vibration of sugar group $(\mathrm{C}=\mathrm{O})^{[34]}$, the absorption band was closely related to the secondary structure of protein. When the absorption peak was at $1652 \mathrm{~cm}^{-1}$, that meant the hydrogen bond formed between $\mathrm{C}=\mathrm{O}$ bond and $\mathrm{N}-\mathrm{H}$ bond contributed to the formation of triple helix structure $^{[35]}$.

The amide band II presented near $1539 \mathrm{~cm}^{-1}$, and the characteristic peak was at $1500-1600 \mathrm{~cm}^{-1}$, which was mainly related to the in-plane bending of $\mathrm{N}-\mathrm{H}$ and $\mathrm{C}-\mathrm{N}$ stretching vibration.

After pre-treatment with US-MW, the position of the absorption band of the amide band III shifted from $1249 \mathrm{~cm}^{-1}$ to
$1246 \mathrm{~cm}^{-1}$, which was related to the degeneration of $\mathrm{N}-\mathrm{H}$ peak, the vibration of $\mathrm{C}-\mathrm{N}$ and the triple helix structure of the protein ${ }^{[36]}$.

The C-N stretching vibration and C-N stretching peak of amide band IV were observed at $1028 \mathrm{~cm}^{-1}$ and $1026 \mathrm{~cm}^{-1}$, respectively from Figures 7 and 8.

In conclusion, the absorption peak of amide band $\mathrm{A}$ and band III shifted after US-MW pre-treatment, which indicated that the $\mathrm{N}-\mathrm{H}$ (hydrogen bonding) stretching vibration and triple helix structure of samples were affected by US-MW treatment.

\section{Conclusions}

The US-MW technique was applied for assisted enzymatic hydrolysis of mussel meat. Based on single-factor experiments and response surface methodology, results showed that the DH is higher compared with traditional methods. Optimum conditions of hydrolysis reaction were ratio of material to liquid at 1:10.36, power at $360.52 \mathrm{~W}$, processing time at $6.91 \mathrm{~min}$ and enzymolysis time of $4 \mathrm{~h}$. Under these conditions, the DH was $48.40 \%$. SDS-PAGE profiles of the hydrolysate revealed that several protein bands were cleaved and several light myosin chains $(25 \mathrm{kDa}$ and $15 \mathrm{kDa}$, respectively) and peptides of molecular weight lower than $6.5 \mathrm{kDa}$ were identified. The infrared spectrum absorption peaks of amide band A and band III shifted after US-MW pre-treatment, which indicated that the $\mathrm{N}-\mathrm{H}$ (hydrogen bonding) stretching vibration and triple helix structure of samples were affected. The amino acid composition analysis showed that glutamic acid, aspartic acid were its main components. These two amino acids were delicious amino acid, thus mussel hydrolysate could be used as a flavoring agent, presenting a good nutritional value.

\section{Acknowledgments}

We would like to express our sincere thanks to Chunrun Biotechnology Co., Ltd. (Jilin Province, China) for the financial and material supports. We also thank the staffs of the Laboratory in Food Science and Engineering.

\section{[References]}

[1] Li G, Li J, Li D. Seasonal variation in nutrient composition of Mytilus coruscus from China. Journal of Agricultural \& Food Chemistry, 2010; 58(13): 7831 .

[2] Zhang H, Xia W S, Xu Y S, Jiang Q X, Wang C X, Wang W J. Effects of spray-drying operational parameters on the quality of freshwater mussel powder. Food \& Bioproducts Processing, 2013; 91(3): 242-248.

[3] Liu C C, Zhou H Y, Su Y C, Li Y S, Li J L. Chemical compositions and functional properties of protein isolated from by-product of triangle shell pearl mussel Hyriopsis cumingii. Journal of Aquatic Food Product Technology, 2009; 18(3): 193-208.

[4] Goulas A E, Chouliara I, Nessi E, Kontominas M G, Savvaidis I N. Microbiological, biochemical and sensory assessment of mussels (Mytilus galloprovincialis) stored under modified atmosphere packaging. Journal of Applied Microbiology, 2005; 98(3): 752-760.

[5] Vernocchi P, Maffei M, Lanciotti R, Suzzi G, Gardini F. Characterization of Mediterranean mussels (Mytilus galloprovincialis) harvested in Adriatic Sea (Italy). Food Control, 2007; 18(12): 1575-1583.

[6] Fuentes A, Fernándezsegovia I, Escriche I, Serra J A. Comparison of physico-chemical parameters and composition of mussels (Mytilus galloprovincialis Lmk.) from different Spanish origins. Food Chemistry, 2009; 112(2): 295-302.

[7] Orban E, Lena G D, Nevigato T, Casini I, Marzetti A, Caproni R Seasonal changes in meat content, condition index and chemical composition of mussels (Mytilus galloprovincialis) cultured in two different Italian sites. Food Chemistry, 2002; 77(1): 57-65.

[8] Goulas A E. Combined effect of chill storage and modified atmosphere packaging on mussels (Mytilus galloprovincialis) preservation. Packaging 
Technology \& Science, 2008; 21(5): 247-255.

[9] Caglak E, Cakli S, Kilinc B. Microbiological, chemical and sensory assessment of mussels (Mytilus galloprovincialis) stored under modified atmosphere packaging. European Food Research \& Technology, 2008; 226(6): 1293-1299.

[10] Wang Y, Wang Z, Handa C L, Xu J. Effects of ultrasound pre-treatment on the structure of $\beta$-conglycinin and glycinin and the antioxidant activity of their hydrolysates. Food Chemistry, 2017; 218: 165.

[11] Zhou Y Y, Zhou M X, Liu J, Liu F X, Huang X Q, Pan S, et al. Effect of high intensity ultrasound on physicochemical and functional properties of soybean glycinin at different ionic strengths. Innovative Food Science \& Emerging Technologies, 2016; 34: 205-213.

[12] Chen L, Chen J X, Ren J Y, Zhao M M. Effects of ultrasound pretreatment on the enzymatic hydrolysis of soy protein isolates and on the emulsifying properties of hydrolysates. Journal of Agricultural \& Food Chemistry, 2011; 59(6): 2600

[13] Wu J J, Zhang K L, Zhou H Y, Tang S W. Study on preparation of soybean protein antioxidant peptides by ultrasonic assisted enzymatic method. Science and Technology of Food Industry, 2012; 33: 212-219. (in Chinese)

[14] Miao W H, Xu X Y, Zhou B, Pan S Y, Wang K Q, Fan C H, et al. Improvement of sugar production from potato pulp with microwave radiation and ultrasonic wave pretreatments. Journal of Food Process Engineering, 2014; 37(1): 86-90.

[15] Leonelli C, Mason T J. Microwave and ultrasonic processing: Now a realistic option for industry. Chemical Engineering \& Processing Process Intensification, 2010; 49(9): 885-900.

[16] Lee C M, Trevino B, Chaiyawat M. A simple and rapid solvent extraction method for determining total lipids in fish tissue. Journal of AOAC International, 1996; 79(2): 487

[17] Undeland I, Kelleher S D, Hultin H O. Recovery of functional proteins from herring (Clupea harengus) light muscle by an acid or alkaline solubilization process. Journal of Agricultural \& Food Chemistry, 2002; 50(25): 7371-7379

[18] Fontaine J, Eudaimon M. Liquid chromato graphic determination of lysine, methionine and threonine in pure amino acids (feed grade) and pre-mixes: Collaborative study. J AOAC Int, 2000; 83: 771-783.

[19] Schägger H, Jagow G V. Tricine-sodium dodecyl sulfate-polyacrylamide gel electrophoresis for the separation of proteins in the range from 1 to 100 kDa. Analytical Biochemistry, 1987; 166(2): 368.

[20] Zhou Y, He Q, Zhou D. Optimization extraction of protein from mussel by high - Intensity pulsed electric fields. Journal of Food Processing \& Preservation, 2017; 41(3).

[21] Chandrapala J, Zisu B, Palmer M, Kentish S, Ashokkumar M. Effects of ultrasound on the thermal and structural characteristics of proteins in reconstituted whey protein concentrate. Ultrasonics Sonochemistry, 2011; 18(5): 951.
[22] Jiang L Z, Wang J, Li Y, Wang Z J, Liang J, Wang R, et al. Effects of ultrasound on the structure and physical properties of black bean protein isolates. Food Research International, 2014; 62(6): 595-601.

[23] Jin J, Ma H L, Wang K, Yagoub A A, Owusu J, Qu W J, et al. Effects of multi-frequency power ultrasound on the enzymolysis and structural characteristics of corn gluten meal. Ultrasonics Sonochemistry, 2015; 24: 55-64.

[24] Kurozawa L E, Park K J, Hubinger M D. Optimization of the enzymatic hydrolysis of chicken meat using response surface methodology. Journal of Food Science, 2008; 73(5): C405-C412.

[25] De Holanda H D, Netto F M. Recovery of components from shrimp (Xiphopenaeus kroyeri) processing waste by enzymatic hydrolysis. Journal of Food Science. 2006; 71(5): C298-C303.

[26] Kim S M. Manufacture of fish hydrolyzate by enzyme. Korean Journal of Food Science \& Technology, 1999.

[27] Hu H, Li B F, Zhao X, Zhang Z H. Optimization of enzymatic hydrolysis of Alaska pollock frame for preparing protein hydrolysates with low-bitterness. LWT - Food Science and Technology, 2011; 44(2): 421-428.

[28] Silva V M, Park K J, Hubinger M D. Optimization of the enzymatic hydrolysis of mussel meat. Journal of Food Science, 2010; 75(1): C36-C42.

[29] Sun H M, Wang J Z, Zhang C H, Li X, Xu X, Dong X B, et al. Changes of flavor compounds of hydrolyzed chicken bone extracts during Maillard reaction. Journal of Food Science, 2015; 79(12): C2415-C2426.

[30] Jr M S. Arginine metabolism in vascular biology and disease. Vascular Medicine, 2005; 10(Supp 1): S83-87.

[31] Turi N A, Farhatullah, Rabbani M A, Khan N U, Akmal M, Pervaiz Z H, et al. Study of total seed storage protein in indigenous Brassica species based on sodium dodecyl sulfate polyacrylamide gel electrophoresis (SDS-PAGE). African Journal of Biotechnology, 2015; 9(45).

[32] Margulis B A, Pinaev G P. The species specifity of the contractile protein composition of the bivalve molluscs. Comparative Biochemistry \& Physiology B Comparative Biochemistry, 1976; 55(2): 189.

[33] Nagai T, Suzuki N, Nagashima T. Collagen from common minke whale (Balaenoptera acutorostrata) unesu. Food Chemistry, 2008; 111(2): 296-301.

[34] Payne K J, Veis A. Fourier transform ir spectroscopy of collagen and gelatin solutions: Deconvolution of the amide I band for conformational studies. Biopolymers, 1988; 27(11): 1749.

[35] Matmaroh K, Benjakul S, Prodpran T, Encarnacion A B, Kishimura H. Characteristics of acid soluble collagen and pepsin soluble collagen from scale of spotted golden goatfish (Parupeneus heptacanthus). Food Chemistry, 2011; 129(3): 1179-1186.

[36] Min Z, Liu W T, Li G Y. Isolation and characterisation of collagens from the skin of largefin longbarbel catfish (Mystus macropterus). Food Chemistry, 2009; 115(3): 826-831. 